\title{
Time for Radical Changes in Brain Stem Nomenclature-Applying the Lessons From Developmental Gene Patterns
}

OPEN ACCESS

Edited by:

Paul Manger,

University of the Witwatersrand,

South Africa

Reviewed by:

Marten P. Smidt,

University of Amsterdam, Netherlands

Adhil Bhagwandin,

University of Cape Town, South Africa

Nina Patzke

Hokkaido University, Japan

${ }^{*}$ Correspondence:

Charles Watson

c.watson@curtin.edu.au

Received: 25 October 2018

Accepted: 22 January 2019

Published: 12 February 2019

Citation:

Watson C, Bartholomaeus C and

Puelles $L$ (2019) Time for Radical

Changes in Brain Stem

Nomenclature-Applying the Lessons

From Developmental Gene Patterns.

Front. Neuroanat. 13:10.

doi: 10.3389/fnana.2019.00010

\author{
Charles Watson ${ }^{1,2 *}$, Caitlin Bartholomaeus ${ }^{1}$ and Luis Puelles ${ }^{3}$ \\ ${ }^{1}$ School of Biological Sciences, University of Western Australia, Perth, WA, Australia, ${ }^{2}$ Neuroscience Research Australia, The \\ University of New South Wales, Sydney, NSW, Australia, ${ }^{3}$ Department of Human Anatomy and IMIB-Arrixaca Institute, \\ School of Medicine, University of Murcia, Murcia, Spain
}

The traditional subdivision of the brain stem into midbrain, pons, and medulla oblongata is based purely on the external appearance of the human brain stem. There is an urgent need to update the names of brain stem structures to be consistent with the discovery of rhomobomeric segmentation based on gene expression. The most important mistakes are the belief that the pons occupies the upper half of the hindbrain, the failure to recognize the isthmus as the first segment of the hindbrain, and the mistaken inclusion of diencephalic structures in the midbrain. The new nomenclature will apply to all mammals. This essay recommends a new brain stem nomenclature based on developmental gene expression, progeny analysis, and fate mapping. In addition, we have made comment on the names given to a number of internal brain stem structures and have offered alternatives where necessary.

Keywords: brain stem, hindbrain, midbrain, isthmus, rhombomeres

\section{INTRODUCTION}

For over a century, teachers and scientists have described the mammalian brain stem as having three parts - the midbrain, the pons, and the medulla oblongata-and the names of numerous structures inside the brain stem are consistent with this subdivision. This subdivision was based purely on the external appearance of the human brain stem and there is an urgent need to update the names of brain stem structures to be consistent with modern research findings relative to molecularly defined brain stem developmental units. Studies of developmental gene expression show that the current use of the term "pons" is in most cases very misleading (Puelles et al., 2013; Watson et al., 2017a). In addition, gross misinterpretations of brain stem organization have led to the mistaken inclusion of diencephalic structures in the midbrain, and the failure to recognize the isthmus as the first segment of the hindbrain. This essay will summarize the problems that have arisen from the conventional use of the traditional brain stem nomenclature, and will suggest alternatives based on developmental gene expression, progeny analysis, and fate mapping. In addition, we will comment on the names given to a number of internal brain stem structures and offer alternatives where we think it necessary.

The key to understanding the "natural" (i.e., gene-modulated) anatomy of the brain stem lies in an appreciation of its segmental rostrocaudal organization, without forgetting its parallel dorsoventral differentiation. A complete picture of the segmental organization has been revealed by a number of studies of gene expression during development, which have been summarized by Puelles et al. (2013) and Tomás-Roca et al. (2016). 


\section{GENE EXPRESSION REVEALS THE SEGMENTAL ORGANIZATION OF THE BRAIN STEM}

The segmental organization of the brain stem was first observed by embryologists in the late nineteenth century, who described a series of outpouchings in the developing vertebrate brain stem (von Baer, 1828; Orr, 1887). The significance of this finding was lost in the subsequent period dominated by the columnar organization theories of Herrick $(1910,1948)$. But over about the past 25 years, the outpouchings have been recognized as evidence for the fundamental segmental organization of the brain stem. The change came about through the advent of studies on developmental gene expression (e.g., Gaunt et al., 1986; Murphy et al., 1989; Wilkinson et al., 1989a,b; Sundin and Eichele, 1990; Krumlauf et al., 1993), the creation of molecularlydefined regional progeny, and clonal restriction (Lumsden and Keynes, 1989; Fraser et al., 1990; Lumsden, 1990, 1991). These gene-based progeny studies were enabled by the invention of gene targeting in mice (Capecchi, 1989). It is now clear that the brain stem of all vertebrates is made up of a rostro-caudal series of segments that arise in early development and impose an anatomical and functional organization that persists in the adult brain. An additional point of significance is that the midbrain has in recent years been ascribed to the forebrain, taking it out of the brain stem. The midbrain has been found to share a number of gene expression patterns with diencephalon and hypothalamus and lacks true continuity with the hindbrain (Puelles, 2013). The midbrain contains two segments, called mesomeres (Puelles et al., 2012a; Puelles, 2013), whereas the hindbrain is divided into 12 neuromeres-the isthmus and 11 rhombomeres (Puelles et al., 2013; Tomás-Roca et al., 2016; Watson et al., 2017a). Unfortunately, some authors (notably those led by Lumsden and Krumlauf) have consistently ignored the significance of the isthmus and have not accepted the existence of the four caudal rhombomeres ( $r 8$ to $\mathrm{r} 11)$, based on the fact that they lack overt constrictions between them (e.g., Lumsden and Krumlauf, 1996; Tümpel et al., 2009). However, the gene expression evidence for the isthmic segment (Watson et al., 2017c) and the presence of four "hidden" rhombomeres, known as cryptorhombomeres, is now very strong (Marín et al., 2008; Puelles, 2013; Puelles et al., 2013; Tomás-Roca et al., 2016). One surprising finding in relation to the caudal rhombomeres is that the pyramidal decussation is located in the spinal cord, and not in the caudal hindbrain as has been traditionally assumed (Tomás-Roca et al., 2016). The pyramidal tract fibers decussate after they cross the medullospinal boundary and so the pyramidal decussation in no longer a component of the hindbrain.

The first comprehensive attempt to illustrate the boundaries and contents of the segmental elements of the brain stem (two mesomeres, isthmus, and 11 rhombomeres) in different planes of section was presented in the chick brain atlas of Puelles et al. (2007). Many of the segments in the brain stem in birds and mammals can be confidently identified by the presence of one or more signature nuclei; examples are the trochlear nucleus in the isthmus and the abducens nucleus in r5. A diagram summarizing mammalian segmental components can be found in Tomás-Roca et al. (2016), and a modified version of this figure is shown in our Figure 4. Table 1 shows the segmental position of selected structures in the mammalian brain stem and adjacent diencephalon and spinal cord.

A relatively small set of genes is involved in establishing the rostrocaudal segmental plan of the central nervous system. Those vital to brain stem development include Pax family genes, Otx2, Wnt1, Gbx2, Fgf8, Shh genes, and Hox family genes. Their role in the segmentation of the brain stem is summarized in Figure 1, which shows that expression of Pax 6 in the alar diencephalon ends sharply at the junction between the pretectal area and the midbrain (Schwarz et al., 1999; see images in Puelles et al., 2012a; Duan et al., 2013), Otx2 is expressed in forebrain and midbrain (Puelles et al., 2012a,b); Gbx2 is expressed in the rostral hindbrain (isthmus and r1) but not in the midbrain (Puelles et al., 2012a); Fgf8 is selectively expressed in the isthmus (Watson et al., 2017c); and the Hox genes are expressed from $\mathrm{r} 2$ to the caudal end of the spinal cord (Puelles et al., 2013). The expression of the Hoxrelated gene Egr2 reveals the anatomy of rhombomeres 3, 4, and 5 in a convincing way (Figure 2).

There is a question as to whether the gene expression data acquired from mice can be confidently applied to other mammals, and perhaps to other vertebrates. We are confident such extrapolations can be made, because the anatomy and development of the brain stem is highly conserved (for a general discussion of this issue see Nieuwenhuys et al., 1998; Gilland and Baker, 2005). For example, the pattern of gene expression in the development of the brain stem in chicks mirrors that described in the mouse in almost every respect, even though the species are separated by around 300 million years of evolution. A few exceptions do exist (such as the translocation of the facial motor nucleus from $\mathrm{r} 4$ to $\mathrm{r} 6$ in mammals), but the point to point similarities are extraordinary (Cambronero and Puelles, 2000; Puelles et al., 2007; Tomás-Roca et al., 2016). However, the evolutionary history of brain stem development is a much bigger subject than we have attempted to address in the present paper.

\section{PROBLEMS WITH TRADITIONAL BRAIN STEM NOMENCLATURE}

When the traditional nomenclature of the brain stem is tested against the new understanding of brain stem organization based on developmental gene expression, five major areas of misinterpretation become apparent. These are the true identity of the pons, the existence of the isthmus, the true definition of the midbrain without diencephalic and hindbrain additions, the location of the substantia nigra and VTA (though this is rather a diencephalon problem), and the segmental origin of the cerebellum.

\section{The True Identity of the Pons}

The primary problem with the use of the word "pons" is that its historical meaning attaches to the voluminous formation seen on the ventral surface of the human brain. The basilar pontine formation is exceptionally large in humans 
TABLE 1 | Segmental components of the mammalian caudal diencephalon, midbrain, and hindbrain and position of major structures within these segments.

\begin{tabular}{|c|c|c|}
\hline \multicolumn{3}{|l|}{ DIENCEPHALON } \\
\hline \multicolumn{3}{|c|}{ Diencephalic prosomere 1 (dp1) } \\
\hline & Posterior commissure & $\mathrm{pc}$ \\
\hline & Pretectal nuclei & PT \\
\hline & Darkschewitsch nucleus & DK \\
\hline & Interstitial nucleus of Cajal & $\ln C$ \\
\hline & Red nucleus, parvocellular part & $\mathrm{RPC}$ \\
\hline \multicolumn{3}{|l|}{ MIDBRAIN } \\
\hline \multirow[t]{5}{*}{ Mesomere 1 (m1) } & Superior colliculus & SC \\
\hline & Inferior colliculus & IC \\
\hline & Oculomotor nucleus & $3 N$ \\
\hline & Emerging oculomotor nerve & $3 n$ \\
\hline & Red nucleus, magnocellular part & $\mathrm{RMC}$ \\
\hline \multirow[t]{3}{*}{ Mesomere 2 (m2) } & Sagulum nucleus & Sag \\
\hline & Retrorubral field (DA8) & RRF \\
\hline & Subbrachial nucleus & SubB \\
\hline \multicolumn{3}{|l|}{ HINDBRAIN } \\
\hline \multicolumn{3}{|c|}{ Isthmocerebellar (prepontine) } \\
\hline \multirow[t]{5}{*}{ Isthmus (is) } & Trochlear nucleus & $4 \mathrm{~N}$ \\
\hline & Emerging trochlear nerve & $4 n$ \\
\hline & Parabigeminal nucleus & PBG \\
\hline & Microcellular tegmental nucleus & MiTg \\
\hline & Prodomal interpeduncular nucleus & IPpro \\
\hline \multirow[t]{4}{*}{ Rhombomere 1 (r1) } & Locus coeruleus & LC \\
\hline & Rostral interpeduncular nucleus & IPR \\
\hline & Caudal interpeduncular nucleus & IPC \\
\hline & Parabrachial nuclei & MPB/LPB \\
\hline \multicolumn{3}{|l|}{ PONTINE REGION } \\
\hline \multirow[t]{2}{*}{ Rhombomere 2 (r2) } & Rostral motor trigeminal nucleus & $5 \mathrm{~N}$ \\
\hline & Emerging motor trigeminal nerve & $5 n$ \\
\hline \multirow[t]{2}{*}{ Rhombomere 3 (r3) } & Caudal motor trigeminal nucleus & $5 \mathrm{~N}$ \\
\hline & Rostral pontine nuclei & $\mathrm{Pn}$ \\
\hline \multirow[t]{2}{*}{ Rhombomere 4 (r4) } & Emerging facial nerve & $7 n$ \\
\hline & Caudal pontine nuclei & $\mathrm{Pn}$ \\
\hline \multicolumn{3}{|l|}{ RETROPONTINE } \\
\hline \multirow[t]{3}{*}{ Rhombomere 5 (r5) } & Abducens nucleus & $6 \mathrm{~N}$ \\
\hline & Emerging abducens nucleus & $6 n$ \\
\hline & Superior olive and trapezoid body & SOl/tz \\
\hline \multirow[t]{2}{*}{ Rhombomere 6 (r6) } & Facial nucleus (migrated) & $7 \mathrm{~N}$ \\
\hline & Emerging glossopharyngeal nerve & $9 n$ \\
\hline \multicolumn{3}{|c|}{ MEDULLA OBLONGATA } \\
\hline Rhombomere 7 (r7) & Compact ambiguus nucleus & AmbC \\
\hline \multirow[t]{2}{*}{ Rhombomere 8 (r8) } & Compact ambiguus nucleus & $\mathrm{AmbC}$ \\
\hline & Rostral inferior olive & 10 \\
\hline \multirow[t]{2}{*}{ Rhombomere 9 (r9) } & Semicompact ambiguus nucleus & AmbsC \\
\hline & Middle inferior olive & 10 \\
\hline \multirow[t]{3}{*}{ Rhombomere 10 (r10) } & Loose ambiguus nucleus & AmbL \\
\hline & Caudal inferior olive & 10 \\
\hline & Area postrema & $\mathrm{AP}$ \\
\hline Rhombomere 11 (r11) & Retroambiguus nucleus & RAmb \\
\hline \multicolumn{3}{|c|}{ ROSTRAL SPINAL CORD } \\
\hline C1 segment & Pyramidal decussation & pyx \\
\hline
\end{tabular}

(correlative with expansion of the cerebral cortex), and this has led to misinterpretation over its true topological position. In many mammals, the basilar pontine nuclei (Pn) and the reticulotegmental nucleus (RtTg) aggregate at the ventral part of rhombomeres 3 and 4 , and the pontine bulge is restricted to the ventral surface of these two rhombomeres. An interesting developmental feature of the basilar pons is that the neurons that form the pontine nuclei develop in the rhombic lip of rhombomeres 6 and 7 and then migrate tangentially under the pia to their final location in rhombomeres 3 and 4 (Figure 2).

On the other hand, human anatomy textbooks uniformly state that the pons extends from the caudal end of the midbrain to the beginning of the medulla oblongata just rostral to the exit of the vestibulocochlear and abducens nerves. The differential growth of the basilar pons in humans hides much of the rostral prepontine hindbrain (from isthmus to part of rhombomere 2 ), on one side, and the part of the retropontine hindbrain containing the abducens nucleus, superior olive, and facial nucleus, on the other (Figures 3, 4).

One result of the superimposition of the human version of pontine topography and nomenclature to those mammals with a small basilar pons is that many structures far away from the basilar pons are called "pontine" because in the human brain they are overlaid by the enlarged "pontine" region. The solution to this problem is relatively simple: discontinue the use of the word "pons" as a topographical descriptor in all mammals, and restrict the use of the term pons to the basilar pontine formation in r3-r4. Note the variable pontine "expansion" into $\mathrm{r} 1$ and $\mathrm{r} 2$ in primate brains lacks any basilar pontine nuclei $(\mathrm{Pn})$ in its interior, and contains exclusively crossed fibers of the middle cerebellar peduncle $(\mathrm{mcp}$ ) that surround the trigeminal root in alar $\mathrm{r} 2$ (see Figure 6). The modern segmented hindbrain model emphasizes the need to distinguish prepontine, pontine, retropontine and medullary territories, each of which appears subdivided into transversal rhombomeric domains. This provides a new level of precision to support modern anatomical and functional analysis.

\section{The Existence of the Isthmus}

The isthmus, understood as a distinct hindbrain segment separating the midbrain from the other hindbrain rhombomeres, was already identified morphologically by His $(1893,1895)$, but was later arbitrarily ascribed to the midbrain in conventional neuroanatomical texts. In contemporary works, the isthmic territory is defined early in development by the selective expression of Fgf8 (coding for the diffusible morphogen FGF8, which serves as the signal of the isthmic organizer-signal needed for the formation of the cerebellum and the caudal midbrain). The mature progeny of the isthmus have been demonstrated in a recent Cre Fgf8 lineage study (Watson et al., 2017c). Within the isthmic territory so defined, lie the trochlear nucleus (and its emerging nerve), the parabigeminal nucleus, the microcellular tegmental nucleus, and the decussation of the superior cerebellar peduncle (Watson et al., 2017c). The isthmus therefore lies between the caudal midbrain and rhombomere 1 (r1).

Most neuroanatomical texts used by health science students do not comment on the presence of the isthmus at all (e.g., 


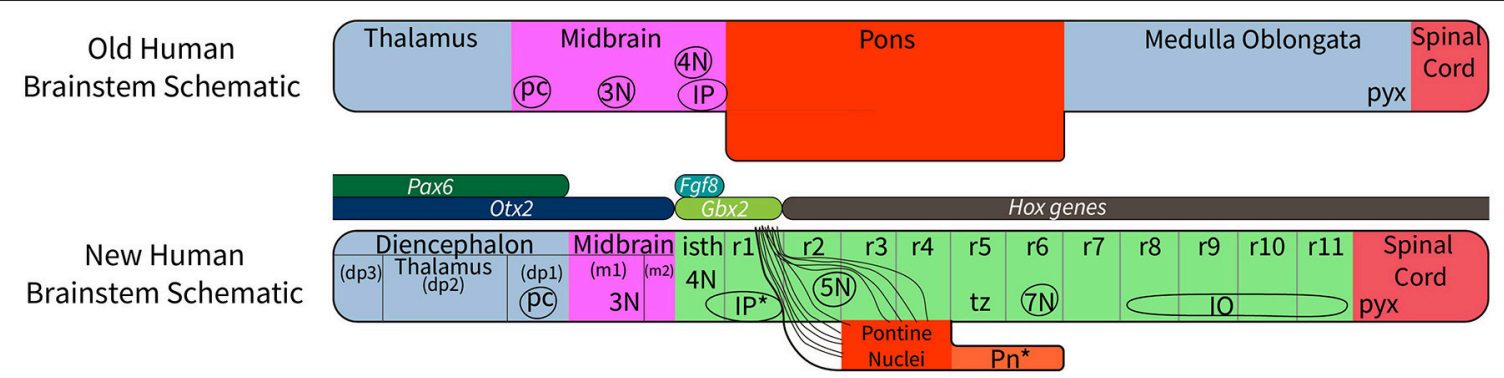

FIGURE 1 | A diagram to compare the traditional view of subdivisions of the human brain stem with the new system of segmentation revealed by developmental gene expression. At the top, the subdivisions of the "old" human brain stem (the traditional version) are based on the assumption that the midbrain extends from the thalamus to the rostral margin of the pons; this concept wrongly holds that the pretectum (dp1) and the isthmus (isth) belong to the midbrain (Puelles et al., 2012a). Comparing the traditional version of the human brain stem with the new segmental schema (bottom schema) we see that the "old" pons was held to extend between levels $r 1$ to r6. In reality, r5 and r6 represent a hidden rostral retropontine part of the "medulla oblongata," whereas the migrated basilar pons is located only within r3 and $\mathrm{r} 4$. Part of the confusion relating to the extent of the pons is due to a mushroom-like rostral expansion of the pons created by rostral pontine cerebellopetal fibers that surround the trigeminal root in $r 2$ as they approach the cerebellum in $r 1$ (see Figure 6), thus adding part of r2 to the apparent pontine bulge in humans. On the other hand, mammals with less massive pontine development than humans show a simpler, less deformed general arrangement, which leaves the ventral surface of r5 and r6 exposed. In addition, the "old" version of the human brain stem places the pyramidal decussation (pyx) at the caudal end of the medullary brain stem, whereas the decussation actually lies in the rostral spinal cord. The most important difference between the "new" human brain stem and the generic mammalian brain stem is that the basilar pons in the human bulges rostrally into r2, where only crossed fibers of the middle cerebellar peduncle are found, and caudally, where the overhanging part of the basilar pontine nuclei partly hides the underlying rhombomeres $r 5$ to $r 6$ ( $\left.\mathrm{Pn}^{*}\right)$. The positions of the oculomotor ( $\left.3 \mathrm{~N}\right)$, trochlear ( $\left.4 \mathrm{~N}\right)$, and facial $(7 \mathrm{~N})$ nerve nuclei, the interpeduncular nuclei (the prodromal, caudal and rostral IP parts are collectively labeled as IP*); the posterior commissure (pc), and the inferior olive are shown for reference. The rostrocaudal extent of key developmental genes is shown in the middle of the diagram. Note Fgf8 codes for the morphogen signal of the isthmic organizer, whose hindbrain gradient ends at the r1/r2 boundary. This image is loosely based on a figure presented by Watson et al. (2017a).

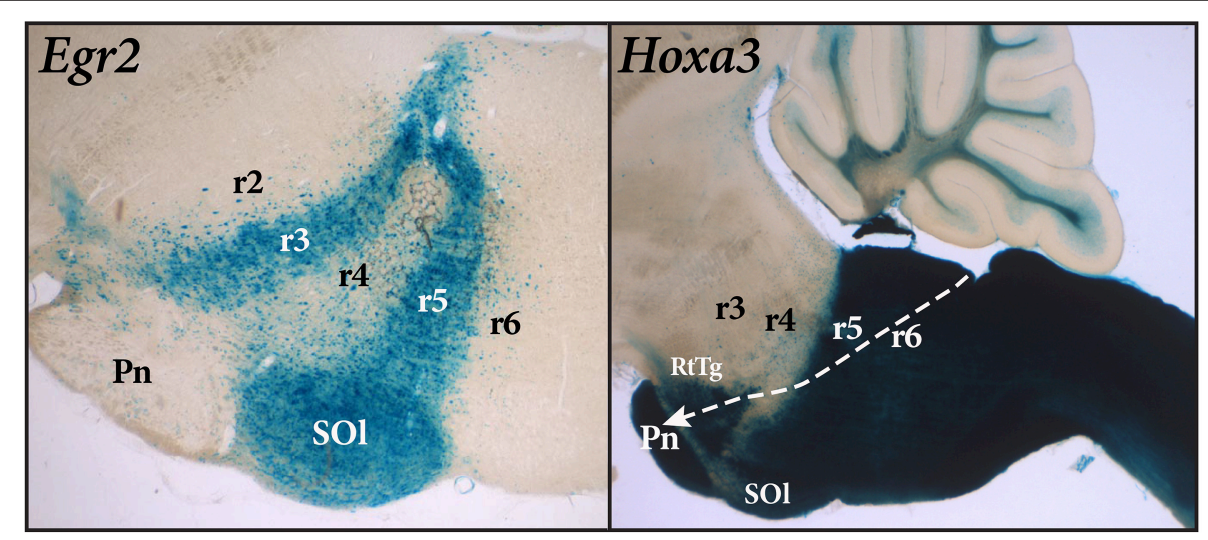

FIGURE 2 | Sagittal sections of mouse brain stem with Egr2-Cre and Hoxa3-Cre fate mapping. The blue Egr2 label is seen in the cells of rhombomere 3 ( $r 3$ ) and rhombomere 5 (r5). Rhombomere 5 contains the labeled cells of the superior olive (SOI), but the pontine nuclei within r4 (Pn), which migrate from r6-r7, remain largely unlabeled. The section on the right, showing expression of Hoxa3, reveals a sharp delineation between rhombomere 4 ( $r 4$ ) and rhombomere 5 ( $r 5$ ). However, the pontine nuclei within $r 3$ and $r 4$, as well as the RtTg nucleus, are labeled in this case because they have migrated from the rhomic lip of rhombomeres 6 and 7 ( $r 6-r 7$ ) as indicated by the path of the white arrow.

Hendelman and Walter, 2005; Haines, 2012; Jacobson et al., 2017; Mtui et al., 2017). A few make note of the organizing role of the isthmic region in the development of the midbrain/hindbrain junction, but do not acknowledge its presence in the mature brain (e.g., Martin, 2003; Nieuwenhuys et al., 2008; Barker et al., 2017). A small number of textbooks recognize the presence of the isthmus in both the developing and developed brain but mistakenly describe it as forming the caudal part of the midbrain (e.g., Butler and Hodos, 2005; Kiernan and Rajakumar, 2013). The modern concept of the isthmus concept establishes a new caudal boundary for the midbrain region, which coincides with the caudal expression limit of the gene Otx2 in all vertebrates (Puelles, 2013; Puelles et al., 2013).

\section{The Mistaken Inclusion of Diencephalic Structures in the Rostral Midbrain and the Modern Rostral Midbrain Boundary}

The diencephalon consists of three segments (diencephalic prosomeres 1, 2, and 3, labeled dp1-3 in Figure 1) defined by gene expression (Puelles et al., 2012a; Puelles, 2013). The caudal diencephalic prosomere ( $\mathrm{dp} 1$ - the pretectal region) is sharply 


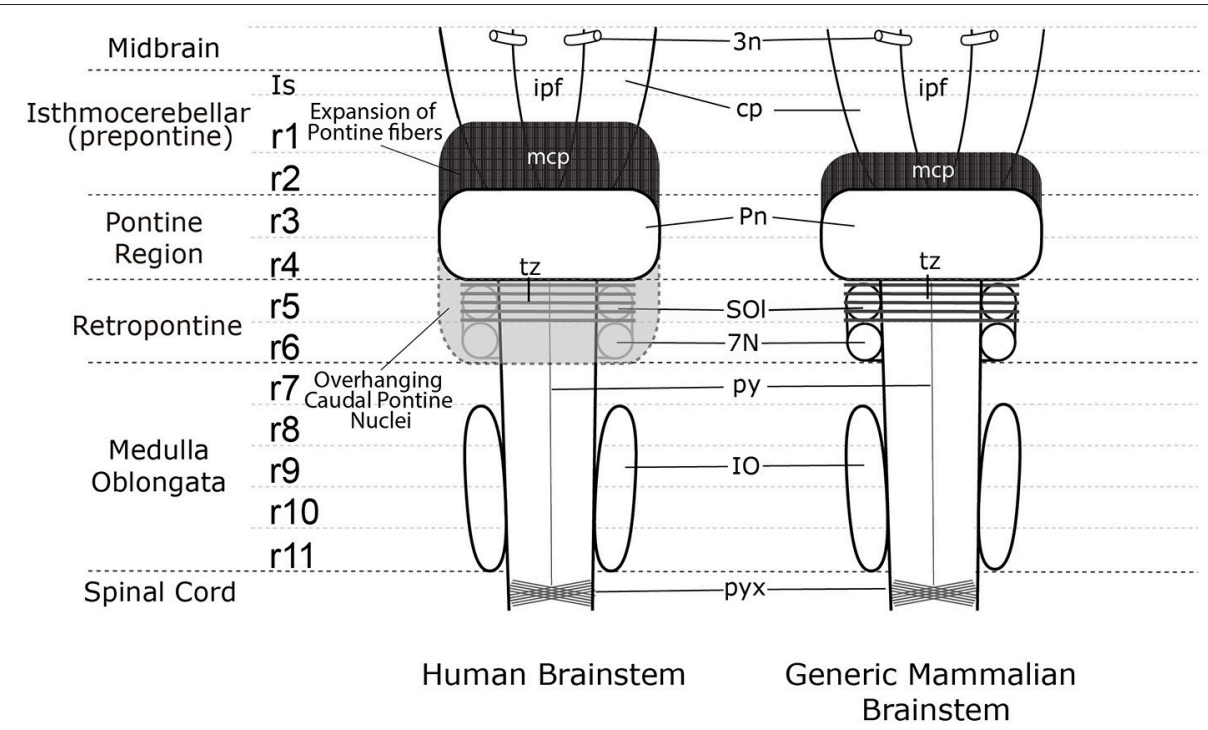

FIGURE 3 | A comparison of the external view of the human brain stem (left) and generic mammalian brain stem (right). In the midbrain the emerging oculomotor nerve $(3 n)$ is shown. Note the interpeduncular fossa extends into the prepontine hindbrain (ipf), where the interpeduncular nuclear complex is found (not shown). The surfaces of the cerebral peduncles (cp) and the interpeduncular fossa (ipf) visible in the human brain stem are reduced by the rostral expansion of the cerebellopetal pontine fibers coursing through $\mathrm{r} 2$ into the cerebellum in $\mathrm{r} 1$ (middle cerebellar peduncle-mcp). The trapezoid body (tz) and superior olive (SOI) identify rhombomere 5 ( $\mathrm{r} 5$ ), but these structures are not visible on the ventral surface of the human brain stem as they are covered by the overhanging caudal pons. The migrated facial nucleus ( $7 \mathrm{~N})$ is found in rhombomere 6 (r6) (Di Bonito et al., 2013; Puelles et al., 2018), but it is also covered by the overhanging caudal expansion of pontine nuclei in the human brain stem. The inferior olive extends from rhombomere $8(r 8)$ to rhombomere $11(r 11)$. The spinal cord begins at the start of the pyramidal decussation (pyx).

separated from the rostral border of the midbrain by a plane passing just behind the posterior commissure and in front of the oculomotor nerve root (Figures 3, 4; Puelles et al., 2012a). Diverse developmental genoarchitectonic studies reveal that a number of caudal diencephalic structures have been mistakenly placed within the boundaries of the midbrain, while experimental analysis has shown that a midbrain fate is incompatible with some genes expressed in the diencephalic pretectum, such as Pax6 (Puelles, 2013, 2016).

These misplaced structures include the nucleus of Darkeschewitz (dp1), the interstitial nucleus of Cajal (dp1), the rostral (parvicellular) red nucleus $(\mathrm{dp} 1)$, the pre-EdingerWestphal nucleus (dp1), the subcommissural organ, the posterior commissure and its related nuclei (dp1), and the medial terminal nucleus of the accessory optic tract (dp1, dp2, and dp3). Moreover, the classical "posterior pretectal nucleus" is now ascribed to the rostral midbrain (m1), since it lies in the rostral part of the superior colliculus, but caudal to the posterior commissure. This nucleus is now named the "tectal gray" (TG, see Figure 4) which is consistent with comparative usage in tetrapods (Puelles et al., 2012a).

A partial explanation for the confusion relating to the rostral and caudal boundaries of the midbrain is lack of appreciation of the impact of the cephalic flexure on giving a marked wedge shape to the midbrain. The cephalic flexure is a sharp bend of almost 180 degrees in the neural axis at the rostral end of the brain stem, so that the ventral surface of the midbrain is compressed into a very small area between the diencephalon and the isthmus, coinciding with the region containing the emerging root of the oculomotor nerve. In a sagittal section, this results in the midbrain forming a wedge shaped profile. In fact, the emerging rootlets of the oculomotor nerve provide the only reliable guide to the identification of the ventral surface of the midbrain (Figure 4; see also Puelles et al., 2012a). Traditional representations of the midbrain have arbitrarily attempted to endow it with a ventral surface of about the same extent as the dorsal (tectal) surface. Based on this error, both textbooks and journal articles placed many structures within the midbrain that actually belong to the isthmus (caudally) or diencephalon (rostrally). The correct location of many of these structures is seen in Figure 4, which shows the boundaries of the midbrain on a diagram of a sagittal section of a rodent brain.

\section{The Location of the Substantia Nigra and the VTA}

A further complication resulting from the severe cephalic flexion of the neuraxis at the level of the midbrain is a misunderstanding of the segmental location of the substantia nigra and the VTA. It is widely assumed that both of these structures lie within the midbrain, but in fact only a caudal portion of both the substantia nigra and the VTA can be found in the compressed true ventral midbrain (Figure 4), and the rostral parts of the substantia nigra and VTA lie in the diencephalon, across its prosomeres 1, 2, and 3. The caudalmost parts of these dopaminergic populations lie in the isthmus (Puelles et al., 2012a,b). The overall result is that only about one quarter of the substantia nigra and VTA can be said to belong to the midbrain, and modern literature refers to a "mesodiencephalic SN/VTA complex." Some differential gene expression has been observed along these four parts of the SN/VTA, suggesting that each segmental module possibly 


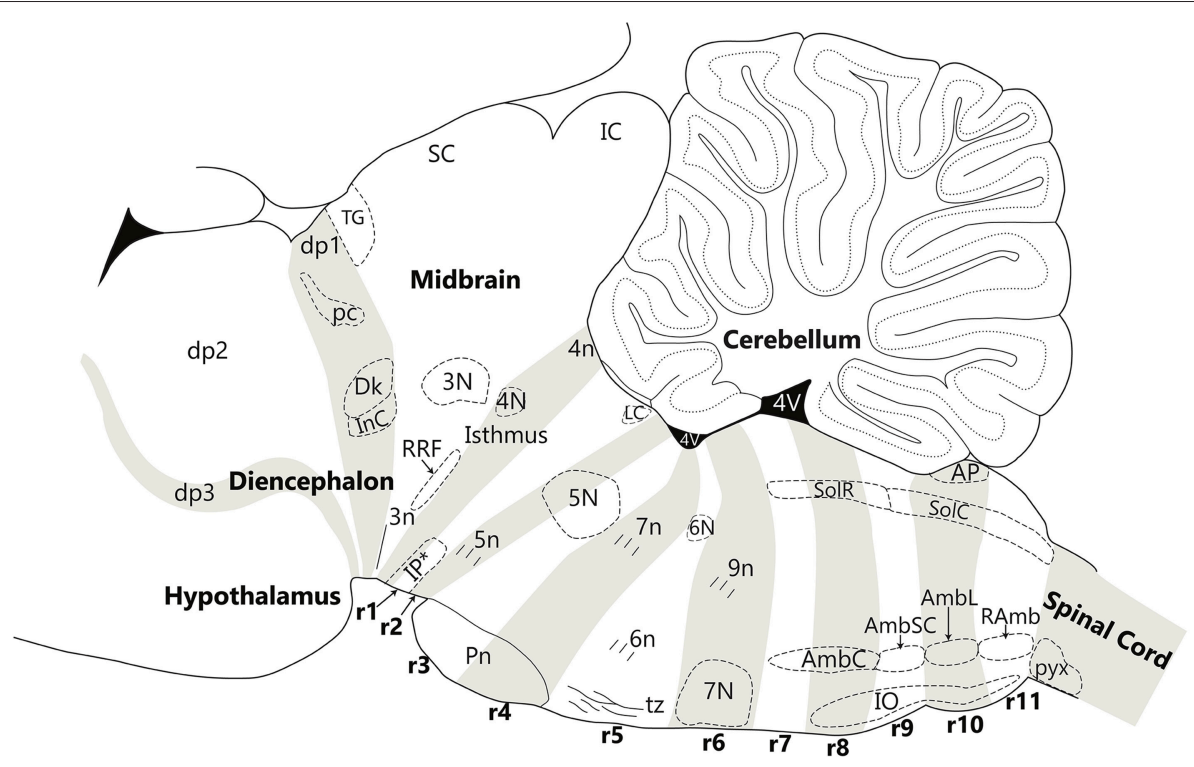

FIGURE 4 | Nuclear and fiber landmarks that identify the segments of the hindbrain, midbrain and diencephalon. In this Figure, the cerebellum, fourth ventricle and hypothalamus are labeled for orientation. Note that fate-mapping data have shown that the cerebellum is a tectal structure restricted to the isthmus and $r 1$, irrespective that in the adult it overhangs far backwards over the dorsal choroidal surface of the pontine, retropontine and medullary regions. The diencephalic prosomere 1 (dp1), which contains the pretectal posterior commissure (pc), Darkschewitsch nucleus (Dk) and the interstitial nucleus of Cajal (InC), is delimited anteroposteriorly by the extent of the posterior commissure $(\mathrm{pc})$. The midbrain contains the oculomotor nucleus $(3 \mathrm{~N})$ and emerging oculomotor nerve $(3 \mathrm{n})$ in mesomere 1 and the retrorubral field (RRF) in mesomere 2. Mesomere 2 is a thin wedge of the midbrain, caudal to $3 \mathrm{~N}$, the red nucleus and the inferior colliculus. The hindbrain is comprised of twelve segments - the isthmus ( $\mathrm{r} 0$ ) and rhombomeres $1-11$ ( $r 1$ to $r 11)$. The isthmus contains the trochlear nucleus (4N), the emerging trochlear nerve (4n) and the prodromal part of the interpeduncular nucleus $\left(I \mathrm{P}^{\star}\right)$. Rhombomere $1(\mathrm{r} 1)$ contains the rostral and caudal parts of the interpeduncular nucleus (IP*), the dorsal and ventral tegmental nuclei, and the locus coeruleus (LC). Rhombomere 2 ( $\mathrm{r} 2)$ contains the rostral part of the motor trigeminal nucleus (5N) and the emerging motor trigeminal nerve. Rhombomere 3 ( $r 3$ ) contains the caudal part of the motor trigeminal nucleus $(5 \mathrm{~N})$ and the rostral pontine nuclei (Pn). Rhombomere 4 ( $r 4)$ contains the caudal pontine nuclei (Pn) and the emerging facial nerve (7n). Rhombomere 5 ( $r 5)$ contains the abducens nucleus (6N), the emerging abducens nerve (6n), and the decussation of the trapezoid body (tz), along with the superior olivary complex. Rhombomere 6 ( $r 6$ ) contains the migrated facial nucleus (7N) and the emerging glossopharyngeal nerve (9n). Rhombomere 7 (r7) and 8 (r8) contain the compact ambiguus nucleus (AmbC) and the rostral end of the solitary nucleus (gustatory nucleus - SolR). Rhombomere 8 also contains the rostral tip of the inferior olive $(\mathrm{IO})$. Rhombomere 9 (r9) contains the semicompact ambiguus nucleus (AmbSC) and the middle region of the inferior olive (IO). Rhombomere 10 ( $\mathrm{r} 10$ ) contains the loose ambiguus nucleus (AmbL), the area postrema (AP), and the caudal region of the inferior olive (IO). Rhombomere 11 ( $r 11$ ) contains the retroambiguus nucleus (RAmb) and the caudal tip of the inferior olive. The spinal cord begins at the start of the pyramidal decussation (pyx).

manifests subtle differential properties (e.g., in projection targets or afferent sources, or in sensitivity to degenerative changes in Parkinson's disease).

\section{The Segmental Origin of the Cerebellum}

The cerebellum is an outgrowth of the dorsalmost alar plate of the caudal isthmus and the first rhombomere (Alvarez-Otero et al., 1993; Aroca and Puelles, 2006). It is therefore an integral part of the prepontine hindbrain, contradicting the old assumption that it forms a developmental unit with the pons. The vermis of the cerebellum is mainly derived from the rhombic lip of the isthmic alar plate, and the hemisphere of the cerebellum is mainly derived from the rhombic lip of the $\mathrm{r} 1$ alar plate, as demonstrated by experimental fate mapping and recent progeny analysis (Alvarez-Otero et al., 1993; Wingate, 2001; Aroca and Puelles, 2006; Watson et al., 2017a,b).

\section{OPTIONS FOR RENAMING PARTS OF THE BRAIN STEM}

The study of developmental gene expression makes it clear that the hindbrain is composed of 12 segments-the isthmus (which can be counted as $\mathrm{r} 0$ ) and the other 11 rhombomeres. The reason referring to the isthmus as $\mathrm{r} 0$ is that the isthmus territory was long thought to develop inside $\mathrm{r} 1$. And once it was realized it was an independent rhombomere [in fact the first one in the series the $\mathrm{r} 0$ convention was adopted to avoid changing all other rhombomere numbers; (Puelles, 2013)]. Embryologists have long considered the isthmus to be a part of the hindbrain, starting from the work of His $(1893,1895)$, and later complemented by Palmgren (1921), Vaage $(1969,1973)$ and Puelles and Martinezde-la-Torre (1987), so the concern as to whether the traditional term "rhombencephalon" includes or not the isthmus seems a moot one.

The solution is to acknowledge the existence of 12 hindbrain rhombomeres ( $\mathrm{r} 0$ to $\mathrm{r} 11$ ) sharing a number of gene determinants and cell fates not present in the midbrain (which should now be considered to form the caudal part of the forebrain). For example, the genes which lead to the specification of serotonergic neurons are found only in rhombomeres 0 to 1 ( $\mathrm{r} 0$ to $\mathrm{r} 11$ ), and are not generated in the midbrain. Note that the newly named r0 element is synonymous with the classic name "isthmus," since this term consistently refers to the rostralmost part of the hindbrain or rhombencephalon. It is important to note again here that the 
cerebellum is a developmental dorsal alar derivative of the $\mathrm{r} 0$ and $\mathrm{r} 1$ units, and so it is also an intrinsic part of the hindbrain. Some previous uses of the term rhombencephalon apparently excluded the cerebellum. The close developmental relationship between the cerebellum and the rostral or, modernly, prepontine hindbrain is not widely appreciated, and the cerebellum is often wrongly treated as if it were an entity separate from the remainder of the brain stem.

There have been various attempts to harmonize or conciliate the parts of the neuromeric hindbrain with the older subdivision into pons and medulla (see Watson et al., 2017a). We suggest dividing the hindbrain into isthmocerebellar or prepontine $(\mathrm{r} 0, \mathrm{r} 1)$, pontine $(\mathrm{r} 2, \mathrm{r} 3$, and $\mathrm{r} 4)$, retropontine ( $\mathrm{r} 5$ and $\mathrm{r} 6$ ) and medullary (r7 to r11) levels (see Figures 5, 6). These divisions provide a logical approach to naming the areas of the hindbrain associated with the pontine regions. This approach retains largely unchanged the use of the term medulla oblongata, which is common to all current textbooks. There may subsist, however, also a need for a larger scale subdivision of the hindbrain for some clinical purposes. We therefore suggest that the region from isthmus ( $\mathrm{r} 0$ ) to rhombomere 6 can be referred to as "rostral hindbrain" and the region from rhombomeres 7 to 11 can be referred to as "caudal hindbrain" (or medulla oblongata) (Figure 5). This definition of the rostral hindbrain includes the isthmocerebellar, pontine and retropontine regions described above. However, we realize that in order to make embryological and physiological rhombomererelated scientific progress accessible to clinical topographic analysis of pathology and surgery within the conventional "pons" region (e.g., modern segmental understanding of motor, reticular, vestibular, auditory, trigeminal, respiratory or cardiocirculatory functional subregions) it may take decades to extinguish its indiscriminative use as a regional descriptor for the whole rostral hindbrain.

\section{Recommended Brain Stem Nomenclature for Different Levels of Learning (High School, Undergraduate University/Medical School)}

The clinical usage of pons and medulla oblongata is primarily based upon the external view of the human hindbrain and is commonly represented in medical student textbooks (see for example Barr's The Human Nervous System 10th edition, Kiernan and Rajakumar, 2013). Figure 5 proposes different levels of nomenclature for the hindbrain required at different levels of education. It is structured such that the lowest level of the nomenclatural understanding (high school human biology) is compatible with the more complex picture allowing a student to build on their initial simpler but already partly updated understanding of the brain stem as they progress into medical school and beyond.

\section{BRAIN STEM NOMENCLATURE IN THE TERMINOLOGICA NEUROANATOMICA}

The 2017 update of Terminologica Neuroanatomica (FIPAT. Terminologica Neuroanatomica. FIPAT.library.dal.ca. Federative
International Program for Anatomical Terminology. February 2017) has attempted to resolve some of the many conflicts in brain stem nomenclature. Overall, the authors have done a fine job of producing a modern nomenclature plan. However, the thickets of nomenclature are dense and challenging and there are many historical hangovers to be dealt with. From the point of view of this paper the best news is that the trochlear nucleus has been moved from the midbrain to the hindbrain. However, a number of rostral hindbrain (isthmic) structures have been unfortunately left in the midbrain. They include the cuneiform nucleus, the parabigeminal nucleus, the caudal linear nucleus, pedunculopontine tegmental nucleus (now properly called peduncular tegmental nucleus because it is nowhere near the pons), and the dorsal raphe nucleus. The latter needs explanation because a small rostral part does invade the midbrain, while the main nucleus stays in the isthmus. The interpeduncular nucleus is also included in the midbrain even though it belongs to $\mathrm{r} 1$.

On the rostral side of the midbrain there are some nuclei which should have been moved to the caudal diencephalon, such as the parvocellular red nucleus.

\section{FURTHER POSSIBLE CHANGES TO TRADITIONAL NAMES OF BRAIN STEM NUCLEI}

In addition to the major nomenclatural issues described above, contemporary research points to the need for recognition of previously unrecognized features of a number of other groups of brain stem nuclei. These nuclei belong to the interpeduncular group, the precerebellar nuclei, the reticular and tegmental nuclei, and the monoaminergic nuclei of the hindbrain.

The Location of Parts of the Interpeduncular Nucleus

The interpeduncular nucleus (IP) occupies a subpial ventral median position associated to the hindbrain part of the interpeduncular fossa (ipf; see Figure 3 and note the classic literature often wrongly ascribed the interpeduncular fossa to the midbrain or even to the diencephalon). The IP is a bilaterally symmetrical complex of diverse subnuclei arranged anteroposteriorly and mediolaterally. The IP receives bilateral forebrain input via the habenulo-interpeduncular tract (facsiculus retroflexus) of both sides. A small rostral part of the interpeduncular nuclear complex has been experimentally demonstrated to originate from the isthmus (Lorente-Cánovas et al., 2012). This represents the prodromal (rostralmost) interpeduncular subnucleus. Caudal to this unit the interpeduncular nucleus has two main parts known as rostral IP (IPR) and caudal IP (IPC). These are located in, and originate from, rhombomere 1 (IPR, IPC; see Figure 6; Lorente-Cánovas et al., 2012).

\section{Precerebellar Nuclei}

The precerebellar nuclei are a set of neuronal populations that generally originate from the hindbrain rhombic lip, variously migrate tangentially to diverse dorsoventral sites within a variety of hindbrain rhombomeres, and project excitatory mossy 

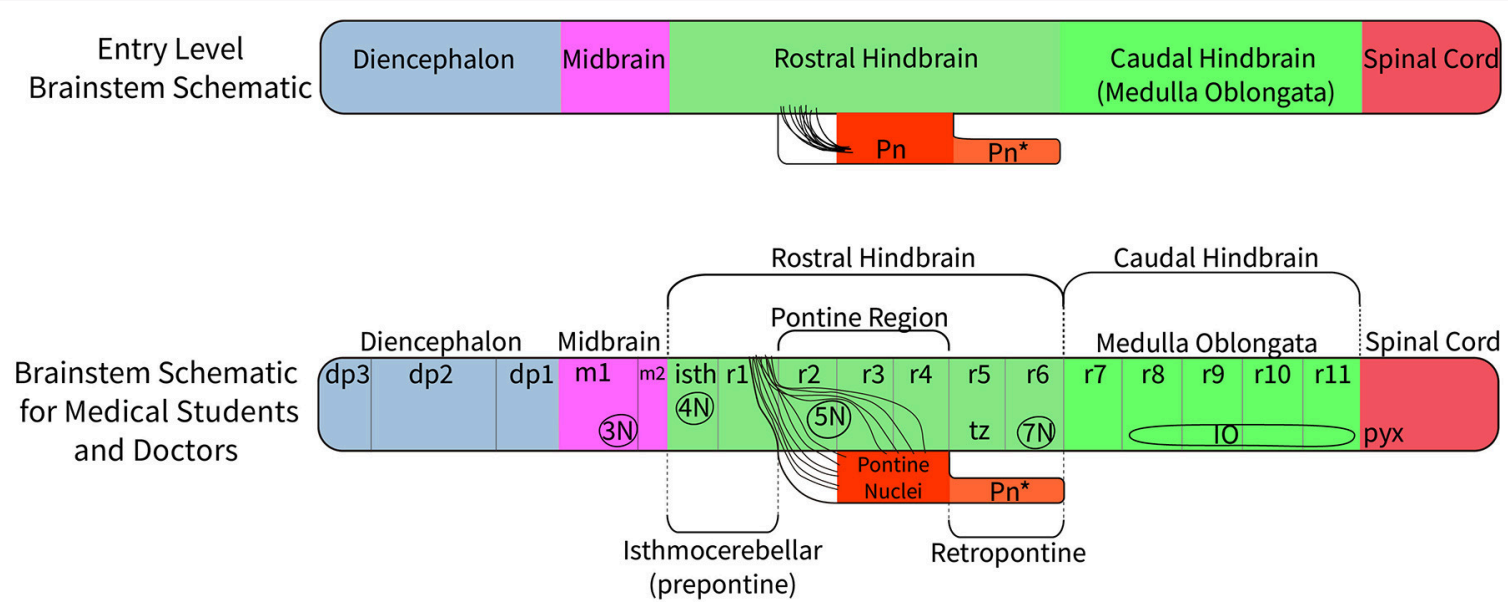

FIGURE 5 | A suggested approach to represent the nomenclature for the diencephalon, midbrain and hindbrain for students at different levels of education. At an entry level (such as a high school level) a student would merely need to understand that on the basis of molecular regionalization there are rostral and caudal parts of the hindbrain. They should know that cerebellar evolutionary enlargement causes the pons (Pn) in primates to form a ventral bulge starting roughly at the middle of the rostral hindbrain, but forming a mushroom-like expansion with pontocerebellar fibers stretching forwards within neighboring rostral hindbrain areas to reach the cerebellum. In humans there is an additional pontine deformation overhanging the ventral surface of the caudalmost rostral hindbrain (Pn*). At a medical student and health professional level, the structures which need to be recognized include the three segments of the diencephalon (dp3, dp2, and dp1), the signature contents of the midbrain (oculomotor nucleus, $3 \mathrm{~N}$, and the emerging oculomotor nerve, not pictured) and the full set of hindbrain rhombomeres (isth/r0-r11). The intermediate hindbrain position of the pontine bulge at $r 2-r 4$, defines the boundaries of the prepontine (r0, $r 1$ or isthmocerebellar) and retropontine ( $r 5$, $r 6$ ) subregions. The pontine nuclei in $r 3$ to $r 4$ give rise to the crossed middle cerebellar peduncle which reaches forward in front and behind the trigeminal root ( $5 \mathrm{n}$ ) in $\mathrm{r} 2$ to enter the cerebellum through r1. In humans, the caudal part of the basilar pontine nuclei overhang, and therefore hide, the most of the ventral surface of rhombomeres 5 and 6 ; thus r 5 and r6 actually represent a distinct retropontine subregion, as a transition into the medullary region (r7 to r11).

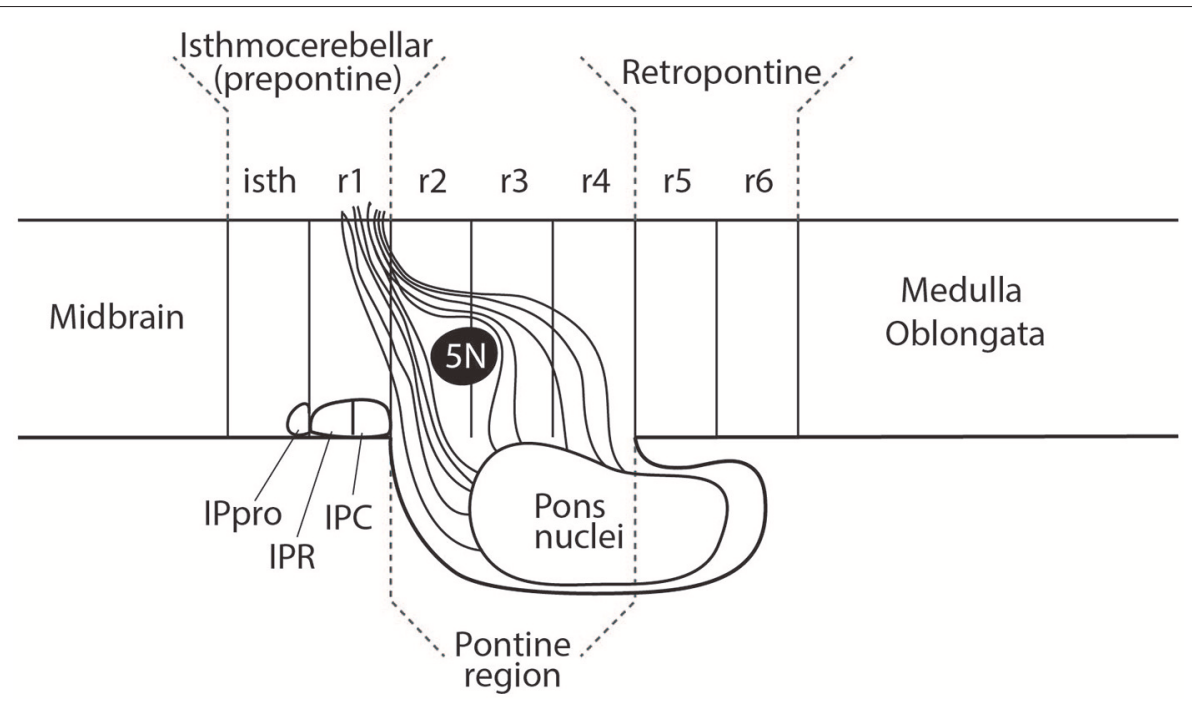

FIGURE 6 | The rostral part of the interpedunclar nucleus (IPR) is often mistakenly placed in the isthmus. This diagram shows the fate-mapped true location of the prodromal interpeduncular subnucleus (IPpro) in the isthmus (isth) and the location of both the IPR and IPC subnuclei in rhombomere 1 ( $r 1$ ). This relates to an apparent subdivision of $r 1$ into distinct rostral and caudal parts, a concept which has received inadequate attention (see Vaage, 1973; Alonso et al., 2012; Puelles, 2013).

fiber input into the cerebellum, mostly contralaterally. The list of such populations includes the basilar pontine nuclei and the reticulotegmental nucleus within $r 3$ to $r 4$, the lateral reticular nuclei, some reticular, trigeminal and vestibular cells, and the external cuneate nucleus. The prepositus hypoglossi nucleus, the intercalated nucleus, and the nucleus of Roller (both medullary) might extend this list. The inferior olive also may be regarded as precerebellar in that sense, but it differs in that its projection ends as climbing fibers within the cerebellum, whereas the others end as mossy fibers. Finally, two previously overlooked hindbrain cell groups have been recently shown to project to the cerebellum. They 
are the linear nucleus and the interfascicular trigeminal nucleus.

\section{The Linear Nucleus-An Extension of the Lateral Reticular Nucleus}

In 2009, Fu et al., showed that a dorsal extension of the lateral reticular nucleus, which they named the linear nucleus, projects to the cerebellum. This nucleus appears to be a constant feature of mammalian brains. However, it should be recognized that the first description of the nucleus, and the original application of the name linear, must be credited to Cajal (Ramon y Cajal, 1904/1995), who described it as forming a part of the lateral reticular nucleus. A segmental analysis of this nucleus in the mouse has recently been completed by Martinez-de-la-Torre et al. (2018).

\section{The Interfascicular Trigeminal Nucleus}

This nucleus had previously been named the tensor tympani part of the motor trigeminal nucleus in rodent brain atlases (Franklin and Paxinos, 2005; Paxinos and Watson, 2007), because it was thought to be a subset of small motor neurons of the motor trigeminal nucleus innervating the tensor tympani muscle. However, the neurons forming the interfascicular trigeminal nucleus were labeled following injection of retrograde tracer in the cerebellum, and the labeled neurons were found to be choline acetyltransferase (ChAT) negative, proving that they are not motor neurons (Fu et al., 2012). In addition, the cells of the interfascicular trigeminal nucleus are strongly labeled in mice via Wnt1Cre and Atoh1CreER lineage fate mapping-a feature common to the major precerebellar nuclei that arise from the rhombic lip and that issue mossy fibers (Fu et al., 2011, 2012).

\section{Reticular and Tegmental Nuclei of the Brain Stem}

Many nuclei in the brain stem that are not directly associated with the cranial nerves or the cerebellum have been labeled as reticular or tegmental nuclei. In the past the reticular nuclei were considered to form a heterogeneous functional group which was divided mainly into pontine and medullary reticular formation domains. This simplistic concept has been abandoned now in favor of a separate consideration of individually named reticular nuclei or cell groups, ascribed if possible to specific rhombomeres, or to rhombencephalic subregions (prepontine, pontine, retropontine, medullary). Unfortunately, some nuclei that have retained the name "reticular" belong to entirely different molecular and functional entities. These include the reticulotegmental and lateral reticular nuclei, which are both precerebellar nuclei. An associated problem is the widespread use of the imprecise term 'ascending reticular activating system.' This usage derives from the work of Moruzzi and Magoun (1949) who famously showed that ascending pathways from the brain stem caused the cerebrum to become alert; they assumed that the brain stem nuclei that gave rise to the ascending activating pathways must reside in the so-called reticular core of the brain stem. This proved to be incorrect, since the hindbrain cell groups that promote wakefulness do not belong to the group of identified reticular nuclei: a series of elegant studies by the Saper group (see Saper et al., 2001) have shown that the hindbrain nuclei that promote wakefulness are the locus coeruleus, the raphe nuclei, and the major forebrain and hindbrain cholinergic nucleinone of which should be considered to belong to the reticular nuclei of the brain stem. Because of this, the term "ascending reticular activating system" should be replaced by the newer term "ascending arousal system."

We wish to draw attention to significant nomenclatural issues relating to some nuclei in the reticular/tegmental group; these are the intermediate reticular zone, the retrorubral (now the retroisthmic nucleus), the pedunculotegmental nucleus, and the nucleus incertus.

\section{The Intermediate Reticular Zone}

In the hindbrain the large cell (gigantocellular) reticular nuclei are medially placed and the small celled (parvicellular) reticular nuclei are laterally placed. The narrow region between these two large groups can be called the intermediate reticular nucleus (IRt).The intermediate reticular (IRt) nucleus of the rat was first recognized by Paxinos and Watson (1986) as a radial zone between the gigantocellular and parvicellular reticular nuclei which is slightly more reactive for $\mathrm{AChE}$ than the adjacent zones. Many peptidergic neurons tend to concentrate there (review in Puelles, 2013). This zone seems to lie next (just lateral) to the plane separating the derivatives of the alar and basal plates, which roughly extends radially from the sulcus limitans in the floor of the fourth ventricle to the pial surface of the brain stem where the vagal and glossopharyngeal rootlets emerge (Martinez-de-laTorre et al., 2018; Puelles et al., 2018). Within the caudal part of the IRt are located the ambiguus and retroambiguus nuclei, the Botzinger (respiratory) nuclei, and the NA1 noradrenaline cell group.

\section{Retrorubral Nucleus}

Two structures in the brain stem have been given the name "retrorubral" - the retrorubral dopaminergic field (A8 dopamine cell group) which lies selectively in $\mathrm{m} 2$ (Puelles et al., 2012a) and the retrorubral tegmental or reticular nucleus, which is located r1. Unfortunately, many papers confuse these two structures and the hindbrain retrorubral nucleus sometimes is described as containing dopamine neurons (probably this error relates to the observed existence of such neurons in the isthmic tegmentum; Puelles et al., 2012a). To avoid this confusion, Paxinos and Watson (2014) renamed the retrorubral nucleus as the "retroisthmic nucleus" since it lies immediately caudal to the caudal boundary of the isthmus. The retroisthmic nucleus is therefore defined as an area in rhombomere 1 between the pedunculotegmental nucleus medially, and the lateral lemniscus and its nuclei laterally. Rostrodorsal to it appears the microcellular tegmental nucleus of the isthmus, and rostral to it is the caudal (isthmic) pole of the substantia nigra.

\section{Pedunculotegmental Nucleus}

The pedunculotegmental nucleus (PTg) is a prominent cholinergic (and NOS positive) cell group in $\mathrm{rl}$, within the rostral hindbrain of the human, monkey, rat, and mouse. Paxinos and Watson (2006) and Puelles et al. (2007) renamed the 
pedunculopontine tegmental nucleus as the pedunculotegmental nucleus (PTg), because it is not a pontine structure and clearly, lying in $\mathrm{r} 1$, it has no close topographical relationship to the pontine nuclei in $\mathrm{r} 3$ and $\mathrm{r} 4$. It is one of many prepontine nuclei given a 'pontine' suffix simply because they lie in the area covered by the rostrally expanded pons in the human brain.

In the human and in the rhesus monkey, the PTg has been described as having a compact cholinergic part (pars compacta) and a diffuse non-cholinergic part (pars dissipata). In rodents, however, Swanson (1992) and Paxinos and Watson (2006) named the non-cholinergic area found lateral to PTg as the retrorubral nucleus. The retrorubral nucleus has never been recognized in primates. Paxinos and Watson (2006) concluded that the retrorubral nucleus of the rodent is, in fact, the homolog of the PTg pars dissipata of primates. A study of AChE sections of human, monkey and rat brains confirms that the PTg in all three species is strongly AChE positive in cells and neuropil. Furthermore, the area immediately lateral to PTg (the primate pars dissipata and the rodent retrorubral nucleus) in all three species is only lightly stained for AChE.

\section{The Incertus Nucleus}

The identity of the incertus nucleus has been questioned since it was originally named by Streeter (1903). The area named by Streeter was quite extensive and includes areas not currently thought to relate to the true incertus nucleus. The current view is that the incertus nucleus lies close to the ependyma of the fourth ventricle, medial and ventral to the posterodorsal tegmental nucleus (PDTg, which lies within basal r2), close to the locus coeruleus in the rat (which lies in lateral basal $r 1$ ), and consists of a medial compact part and a lateral diffuse part. The two parts of the incertus nucleus were given different names in the influential rabbit brain atlas of Meessen and Olszewski (1949). Meessen and Olzewski named the compact part as 'nucleus $\mathrm{O}$ of the central gray,' and called the diffuse part 'the alpha part of the central gray.' In a series of editions of the widely cited rat brain atlas (Paxinos and Watson, 1986, 1997, 1998, 2005, 2006, 2014), the authors continued to use the Meessen and Olzewski terminology. However, because the extensive recent experimental literature on the incertus nucleus has not adopted the Meessen and Olzewski nomenclature (e.g., Goto et al., 2001; Olucha-Bordonau et al., 2003; Ma et al., 2009), we feel it is time to abandon the Meessen and Olzewski terms (nucleus $\mathrm{O}$ and alpha parts of the central gray) in favor of the accepted modern names for the compact and diffuse parts of the incertus nucleus.

\section{Monoaminergic Nuclei in the Brain Stem}

Monoamine groups in the brain stem were first demonstrated by Dahlström and Fuxe (1964) using the method of formalin vaporinduced fluorescence. The original description of the anatomy of these groups was further developed by Fuxe et al. (1970) and Hökfelt et al. (1974) and many subsequent publications by this group. The fluorescent cell groups were originally given arbitrary names (A1, A2 etc. and B1, B2 etc.), and these alphanumeric titles do not provide information concerning the function of the different groups. Because of this, we recommend following the nomenclature adopted by Paxinos et al. (2012) in their atlas of the marmoset brain, and subsequently adopted in atlases of the rat brain (Paxinos and Watson, 2014) and mouse brain (Paxinos and Franklin, 2013). Paxinos et al. (2012) named dopamine groups with the prefix DA, noradrenalin groups with the prefix NA, and adrenaline groups with the prefix Ad. However, we have retained the name of locus coeruleus for the previously named A6 group, and the name supralemniscal nucleus for the B9 serotonin group. Similarly, we have retained the names retrorubral field (RRF), substantia nigra compact part (SNC), and ventral tegmental area (VTA) for the dopamine groups previously defined as A8, A9, and A10 (Paxinos et al., 2012).

\section{Many Previously Unrecognized Brain Stem Nuclei Have Appeared in Atlases Since 1982}

The various editions of the Paxinos and Watson rat brain atlas since 1982 have identified and named many brain stem nuclei that had not been defined in previous atlases. Many of these newly identified nuclei have since been identified in atlases of the brains of the mouse (Paxinos and Franklin, 2013), marmoset (Paxinos et al., 2012), rhesus monkey (Paxinos et al., 2009), and human (Paxinos et al., 2018). These newly identified nuclei include the rhabdoid nucleus, the interstitial nucleus of the superior cerebellar peduncle, and the trigeminosolitary transition zone.

\section{THE USE OF EPONYMS}

Over the last 50 years there has been a sensible push to reduce the number of eponyms used in describing neuroanatomical features, and there is a logical argument to remove them all. However, we agree with Paxinos and Watson (2014) that there is no real prospect of expunging a small number of famous and popular eponyms in relation to the brain stem, and we should simply accept their existence. We would therefore retain Barrington's nucleus, the nucleus of Darkschewitsch, the nucleus of Roller, the interstitial nucleus of Cajal, the Edinger-Westphal nucleus, and the cap of Kooy (inferior olive). We observe that in recent years we have also been forced to accept one new eponym-that of Botzinger.

\section{RECOMMENDATIONS}

1. Abandon the subdivision of the hindbrain into "pons" and "medulla."

2. Restrict the use of the term 'pons' to refer to the nuclei and fiber bundles of the basilar pontine formation.

3. Recognize the isthmus (rhombomere 0) as the first segment of the hindbrain.

4. Recognize that the cerebellum is a derivative of the rostral prepontine hindbrain.

5. Recognize that the posterior commissure and associated nuclei, the nucleus of Darkshewitsch, the interstitial nucleus of Cajal, and the rostral part of the red nucleus 
belong to the caudal diencephalon and not to the midbrain.

6. Consider the evidence for including the midbrain in the forebrain on genoarchitectural grounds, which would have the effect of making the old term "brain stem" synonymous with the hindbrain.

7. Adopt a modern functional and segmental nomenclature for the classification of the monoamine cell groups of the brain stem (see Alonso et al., 2012 for serotonergic cell groups of the hindbrain raphe).

\section{REFERENCES}

Alonso, A., Merchán, P., Sandoval, J. E., Sánchez-Arrones, L., Garcia-Cazorla, A., Artuch, R., et al. (2012). Development of the serotonergic cells in murine raphe nuclei and their relations with rhombomeric domains. Brain Struct. Funct. 218, 1229-1277. doi: 10.1007/s00429-012-0456-8

Alvarez-Otero, R., Sotelo, C., and Alvarado-Mallart, R. M. (1993). Chick/quail chimeras with partial cerebellar grafts: an analysis of the origin and migration of cerebellar cells. J. Comp. Neurol. 333, 597-615.

Aroca, P., and Puelles, L. (2006). Postulated boundaries and differential fate in the developing rostral hindbrain. Brain Res. Rev. 49, 179-190. doi: 10.1016/j.brainresrev.2004.12.031

Barker, R. A., Cicchetti, F., and Robinson, E. S. J. (2017). Neuroanatomy and Neuroscience at a Glance. Newark. NJ: John Wiley \& Sons.

Butler, A. B., and Hodos, W. (2005). Comparative Vertebrate Neuroanatomy: Evolution and Adaptation. Hoboken, NJ: John Wiley \& Sons.

Cambronero, F., and Puelles, L. (2000). Rostrocaudal nuclear relationships in the avian medulla oblongata: a fate map with quail chick chimeras. J. Comp. Neurol. 427, 522-545. doi: 10.1002/1096-9861(20001127)427:43.0.CO;2-Y

Capecchi, M. R. (1989). The new mouse genetics: altering the genome by gene targeting. Trends Genet. 5, 70-76.

Dahlström, A., and Fuxe, K. (1964). Evidence for the existence of monoamine containing neurons in the central nervous system. 1. Demonstration of monoamines in the cell bodies of brain stem neurons. Acta Physiol. Scand. 62(Suppl. 232), 3-55.

Di Bonito, M., Narita, Y., Avallone, B., Sequino, L., Mancuso, M., Andolfi, G., et al. (2013). Assembly of the auditory circuitry by a Hox genetic network in the mouse brainstem. PLoS Genet. 9:e1003249. doi: 10.1371/journal.pgen.1003249

Duan, D., Fu, Y., Paxinos, G., and Watson, C. (2013). Spatiotemporal expression patterns of Pax6 in the brain of embryonic, newborn, and adult mice. Brain Struct. Funct. 218, 353-372. doi: 10.1007/s00429-0120397-2

Franklin, K., and Paxinos, G. (2005). The Mouse Brain in Stereotaxic Coordinates. $3^{\text {rd }}$ Edn. San Diego, CA: Elsevier Academic Press.

Fraser, S., Keynes, R., Lumsden, A. (1990). Segmentation in the chick embryo hindbrain is defined by cell lineage restrictions. Nature 344, 431-435.

Fu, Y., Tvrdik, P., Makki, N., Machold, R., Paxinos, G., and Watson, C. (2012). The interfascicular trigeminal nucleus - a precerebellar nucleus in the mouse defined by retrograde tracing and gene expression. J. Comp. Neurol. 521, 697-708. doi: 10.1002/cne.23200

Fu, Y., Tvrdik, P., Makki, N., Paxinos, G., and Watson, C. (2011). Precerebellar cell groups in the hindbrain of the mouse defined by retrograde tracing and correlated with cumulative Wnt1-cre genetic labeling. Cerebellum 10, 570-584. doi: 10.1007/s12311-011-0266-1

Fuxe, K., Hökfelt, T., and Ungerstedt, U. (1970). Morphological and functional aspects of central monoamine neurons. Int. Rev. Neurobiol. 13, 93-126.

Gaunt, S. J., Miller, J. R., Powell, D. J., and Duboule, D. (1986). Homoeobox gene expression in mouse embryos varies with position by the primitive streak stage. Nature 324, 662-664.

Gilland, E., and Baker, R. (2005). Evolutionary patterns of cranial nerve efferent nuclei in vertebrates. Brain Behav. Evol. 66, 234-254. doi: 10.1159/000088128

\section{AUTHOR CONTRIBUTIONS}

LP was primarily responsible for the direction of this research. CW was responsible for the design of the paper. All three authors contributed equally to the writing of this paper.

\section{FUNDING}

The work of LP was supported by funding from the SENECA Foundation (Murcia) 19904/GERM/15.

Goto, M., Swanson, L. W., and Canteras, N. S. (2001). Connections of the nucleus incertus. J. Comp. Neurol. 438, 86-122. doi: 10.1002/cne.1303

Haines, D. E. (2012). Neuroanatomy: An Atlas of Structures, Section, and Systems. 8th Edn. Philadelphia, PA: Lippincott William \& Wilkins.

Hendelman, M. D., and Walter, J. (2005). Atlas of Functional Neuroanatomy. 2nd Edn. Baton Rouge, LA: CRC Press.

Herrick, C. J. (1910). The morphology of the forebrain in amphibia and reptilia. J. Comp. Neurol. 20, 413-547.

Herrick, C. J. (1948). The Brain of the Tiger Salamander, Ambystoma Tigrinum. Chicago, IL: University of Chicago Press.

His, W. (1893). Vorschläge zur Eintheilung des Gehirns. Arch. Anat. Entwickl Gesch. Jahrg. 1893, 173-179.

His, W. (1895). Die anatomische nomenclatur, nomina anatomica. Neurol. Suppl. Bd. Arch. Anat. Entwickl Gesch. Jahrg. 1895, 155-177.

Hökfelt, T., Fuxe, K., and Johansson, O. (1974). Immunochemical evidence for the existence of adrenaline containing neurons in the rat brain. Brain Res. 66, 235-2551.

Jacobson, S., Marcus, E. M., and Pugsley, S. (2017). Neuroanatomy for the Neuroscientist. Cham: Springer

Kiernan, J., and Rajakumar, R. (2013). Barr's The Human Nervous System: An Anatomical Viewpoint. Philadephia, PA: Lippincott Williams \& Wilkins.

Krumlauf, R., Marshall, H., Studer, M., Nonchev, S., Sham, M. H., and Lumsden, A. (1993). Hox homeobox genes and regionalisation of the nervous system. J. Neurobiol. 24, 1328-1340.

Lorente-Cánovas, B., Marín, F., Corral-San-Miguel, R., Hidalgo-Sánchez, M., Ferrán, J. L., Puelles, L., et al. (2012). Multiple origins, migratory paths and molecular profiles of cells populating the avian interpeduncular nucleus. Dev. Biol. 361, 12-26. doi: 10.1016/j.ydbio.2011.09.032

Lumsden, A. (1990). The cellular basis of segmentation in the developing hindbrain. Trends Neurosci. 13, 329-335.

Lumsden, A. (1991). Cell lineage restrictions in the chick embryo hindbrain. Philos. Trans. R. Soc. Lond. B Biol. Sci. 331, 281-286.

Lumsden, A., and Keynes, R. (1989). Segmental patterns of neuronal development in the chick hindbrain. Nature 337, 424-428.

Lumsden, A., and Krumlauf, R. (1996). Patterning the vertebrate neuraxis. Science 274, 1109-1115

Ma, S., Olucha-Bordonau, F. E., Hossain, M. A., Lin, F., Kuei, C., Liu, C., et al. (2009). Modulation of hippocampal theta oscillations and spatial memory by relaxin-3 neurons of the nucleus incertus. Learn. Mem. 16, 730-742. doi: 10.1101/lm.1438109

Marín, F., Aroca, P., and Puelles, L. (2008). Hox gene colinear expression in the avian medulla oblongata is correlated with pseudorhombomeric domains. Devel. Biol. 323, 230-247. doi: 10.1016/j.ydbio.2008.08.017

Martin, J. H. (2003). Neuroanatomy: Text and Atlas. 3rd Edn. New York, NY: McGraw-Hill.

Martinez-de-la-Torre, M., Lambertos, A., Peñafiel, R., and Puelles, L. (2018). An exercise in brain genoarchitectonics: Analysis of AZIN2-Lacz expressing neuronal populations in the mouse hindbrain. J Neurosci. Res. 96:1490-1517. doi: 10.1002/jnr.24053

Meessen, H., and Olszewski, J. (1949). A Cytoarchitectonic Atlas of the Rhombencephalon of the Rabbit. Basel: S Karger. 
Moruzzi, G., and Magoun, H. W. (1949). Brain stem reticular formation and activation of the EEG. Electroenceph. Clin. Neurophysiol. 1, 455-473

Mtui, E., Gruener, G., Dockery, P., and Fitzgerald, M. J. T. (2017). Fitzgerald's Clinical Neuroanatomy and Neuroscience. 7th Edn. Philadelphia, PA: Elsevier

Murphy,. P., Davidson, D. R., and Hill, R. E. (1989). Segment-specific expression of a homoeobox-containing gene in the mouse hindbrain. Nature 341, $156-159$.

Nieuwenhuys, R., ten Donkelaar, H. J., and Nicholson, C. (1998). The Central Nervous System of Vertebrates. Berlin: Springer.

Nieuwenhuys, R., Voogd, J., and Huijzen, C., van (2008). The Human Central Nervous System, 4th Edn. New York, NY: Springer.

Olucha-Bordonau, F. E., Teruel, V., Barcia-González, J., Ruiz-Torner, A., ValverdeNavarro, A. A., and Martínez-Soriano, F. (2003). Cytoarchitecture and efferent projections of the nucleus incertus of the rat. J. Comp. Neurol. 464, 62-97. doi: $10.1002 /$ cne.10774

Orr, H. (1887). Contribution to the embryology of the lizard; With especial reference to the central nervous system and some organs of the head; together with observations on the origin of the vertebrates. J. Morph. 1, 311-372.

Palmgren, A. (1921). Embryological and morphological studies on the midbrain and cerebellum of vertebrates. Acta Zool. 2, 1-94.

Paxinos, G., and Franklin, K. (2013). Paxinos and Franklin's The Mouse Brain in Stereotaxic Coordinates, 4th Edn. San Diego, CA: Elsevier Academic Press.

Paxinos, G., Furlong, T., and Watson, C. (2018). Human Brain stem - Cytoarchitecture, Chemoarchitecture, Myeloarchitecture. San Diego, CA: Elsevier Academic Press.

Paxinos, G., Huang, X.-F., and Toga, A. W. (2009). The Rhesus Monkey Brain in Stereotaxic Coordinates, 2nd Edn. San Diego, CA: Elsevier Academic Press.

Paxinos, G., and Watson, C. (1986). The Rat Brain in Stereotaxic Coordinates, 2nd Edn. San Diego: Academic Press.

Paxinos, G., and Watson, C. (1997). The Rat Brain in Stereotaxic Coordinates, Compact 3rd Edn. San Diego, CA: Academic Press.

Paxinos, G., and Watson, C. (1998). The Rat Brain in Stereotaxic Coordinates, 4th Edn. San Diego, CA: Academic Press.

Paxinos, G., and Watson, C. (2005). The Rat Brain in Stereotaxic Coordinates, 5th Edn. San Diego, CA: Elsevier Academic Press.

Paxinos, G., and Watson, C. (2006). The Rat Brain in Stereotaxic Coordinates, 6th Edn. San Diego, CA: Elsevier Academic Press.

Paxinos, G., and Watson, C. (2007). The Rat Brain in Stereotaxic Coordinates. Sydney, NSW: Academic Press.

Paxinos, G., and Watson, C. (2014). Paxinos and Watson's The Rat Brain in Stereotaxic Coordinates, 7th Edn. San Diego, CA: Elsevier Academic Press.

Paxinos, G., Watson, C., Petrides, M., Rosa, M., and Tokuno, H. (2012). The Marmoset Brain in Stereotaxic Coordinates. San Diego, CA: Elsevier Academic Press.

Puelles, E., Martínez-de-la-Torre, M., Watson, C., and Puelles, L. (2012a). "Midbrain," in The Mouse Nervous System, eds C. Watson, G. Paxinos, and L. Puelles (San Diego, CA: Elsevier Academic Press), 337-359.

Puelles, L. (2013). "Plan of the developing vertebrate nervous system relating embryology to the adult nervous system (prosomere model,overview of brain organization)," in Comprehensive Developmental Neuroscience: Patterning and Cell Type Specification in the Developing CNS and PNS, eds J. L. R. Rubenstein and P. Rakic (Amsterdam: Academic Press), 187-209.

Puelles, L. (2016). Comments on the limits and internal structure of the mammalian midbrain. Anatomy 10, 60-70. doi: 10.2399/ana.15.045

Puelles, L., Harrison, M., Paxinos, G., and Watson, C. (2013). A developmental ontology for the mammalian brain based on the prosomeric model. Trends Neurosci. 36, 570-578. doi: 10.1016/j.tins.2013.06.004

Puelles, L., and Martinez-de-la-Torre, M. (1987). Autoradiographic and Golgi study on the early development of $\mathrm{n}$. isthmi principalis and adjacent grisea in the chick embryo: a tridimensional viewpoint Anat. Embryol. 176, 19-34. doi: 10.1007/BF00309748

Puelles, L., Martínez-de-la-Torre, M., Ferran, J.-L., and Watson, C. (2012b). "Diencephalon," in The Mouse Nervous System, eds C. Watson, G. Paxinos, and L. Puelles (San Diego, CA: Elsevier Academic Press), 313-336.
Puelles, L., Martínez-de-la-Torre, M., Paxinos, G., Watson, C., and Martínez, S. (2007). The Chick Brain in Stereotaxic Coordinates: an Atlas Featuring Neuromeric Subdivisions and Mammalian Homologies. San Deigo, CA: Elsevier Academic Press.

Puelles, L., Tvrdik, P., and Martínez-de-la-Torre, M. (2018). The postmigratory alar topography of visceral cranial nerve efferents challenges the classical model of hindbrain columns. Anat. Rec. Apr. 16, 2018. doi: 10.1002/ar.23830

Ramon y Cajal, S. (1904/1995). Histology of the Nervous System of Man and Vertebrates, Vol 2. New York, NY: Oxford University Press, 771-773.

Saper, C. B., Chou, T. C., and Scammell, T. E. (2001). The sleep switch: hypothalamic control of sleep and wakefulness. Trends Neurosci 24, 726-731. doi: 10.1016/S0166-2236(00)02002-6

Schwarz, M., Alvarez-Bolado, G., Dressler, G., Urbánek, P., Busslinger, M., and Gruss, P. (1999). Pax2/5 and Pax6 subdivide the early neural tube into three domains. Mech. Devel. 82, 29-39.

Streeter, G. L. (1903). Anatomy of the floor of the fourth ventricle. The relations between the surface markings and the underlying structures. Am. J. Anat. 2, 299-313.

Sundin, O. H., and Eichele, G. (1990). A homeo domain protein reveals the metameric nature of the developing chick hindbrain. Genes Dev. 4, 1267-1276.

Swanson, L. W. (1992). Brain Maps: Structure of the Brain. Amsterdam: Elsevier

Tomás-Roca, L., Corral-San-Miguel, R., Aroca, P., Puelles, L., and Marín, F. (2016). Crypto-rhombomeres of the mouse medulla oblongata, defined by molecular and morphological features. Brain Struct. Funct. 221, 815-838. doi: 10.1007/s00429-014-0938-y

Tümpel, S., Weidemann, L. M., and Krumlauf, R. (2009). "Hox genes and the segmentation of the vertebrate hindbrain," in Hox Genes, ed R. Pourquié (San Diego, CA, Elsevier Academic Press), 103-138.

Vaage, S. (1969). The segmentation of the primitive neural tube in chick embryos (Gallus domesticus). Ergeb. Anat. Entwicklungsgesch. 41, 1-88.

Vaage, S. (1973). The histogenesis of the isthmic nuclei in chick embryos (Gallus domesticus).I. A morphological study. Z. Anat. Entwicklungsgesch 142, 283-314.

von Baer, K. E. (1828). Über Entwickelungsgeschichte der Thiere: Beobachtung und Reflexion. Königsberg: Bornträger.

Watson, C., Kirkcaldie, M., and Puelles, L. (2017a). "Developmental gene expression redefines the Mammalian brain stem," in Evolution of Nervous Systems, 2nd Edn, ed J. Kaas (Oxford: Elsevier), 467-475.

Watson, C., Mitchelle, A., and Puelles, L. (2017b). "A new mammalian brain ontology based on developmental gene expression," in Evolution of Nervous Systems, 2nd Edn, ed J. Kaas (Oxford: Elsevier), 53-75.

Watson, C., Shimogori, T., and Puelles, L. (2017c). Mouse Fgf8-Cre-LacZ lineage analysis defines the territory of the postnatal mammalian isthmus. J. Comp. Neurol. 525, 2782-2799. doi: 10.1002/cne.24242

Wilkinson, D. G., Bhatt, S., Chavrier, P., Bravo, R., and Charnay, P. (1989a). Segment-specific expression of a zinc-finger gene in the developing nervous system of the mouse. Nature 337, 461-464.

Wilkinson, D. G., Bhatt, S., Cook, M., Boncinelli, E., and Krumlauf, R. (1989b). Segmental expression of Hox-2 homeobox-containing genes in the developing mouse hindbrain. Nature 341, 405-409.

Wingate, R. J. (2001). The rhombic lip and early cerebellar development. Curr. Opin. Neurobiol. 11, 82-88. doi: 10.1016/S0959-4388(00)00177-X

Conflict of Interest Statement: The authors declare that the research was conducted in the absence of any commercial or financial relationships that could be construed as a potential conflict of interest.

Copyright (C) 2019 Watson, Bartholomaeus and Puelles. This is an open-access article distributed under the terms of the Creative Commons Attribution License (CC BY). The use, distribution or reproduction in other forums is permitted, provided the original author(s) and the copyright owner(s) are credited and that the original publication in this journal is cited, in accordance with accepted academic practice. No use, distribution or reproduction is permitted which does not comply with these terms. 